\title{
Seasonal changes in the density and vertical distribution of nauplii, copepodites and adults of the genera Oithona and Oncaea (Copepoda) in the surface water of Toyama Bay, southern Sea of Japan
}

\author{
TAKASHI TAKAHASHI ${ }^{1 *} \&$ ISAMU UCHIYAMA ${ }^{2}$ \\ ${ }^{1}$ Jouetsu Environmental Science Center, 1666 Shimomonzen, Jouetsu Niigata 942-0063, Japan \\ ${ }^{2}$ Toyama Prefectural Fisheries Research Institute, 364 Nakatsuka, Namerikawa, Toyama 936-8536, Japan
}

Received 3 April 2006; Accepted 26 February 2008

\begin{abstract}
In this study, we examined seasonal changes in the vertical population density of each developmental stage (nauplius and copepodite) of Oithona and Oncaea species in the surface water of Toyama Bay from 1997 to 1999 . Furthermore, we investigated the detailed vertical distribution $(0 \mathrm{~m}, 25 \mathrm{~m}$ and $50 \mathrm{~m}$ depth $)$ of the naupliar stages, which are regarded as an important food source for fish larvae. Major changes in the community structure of nauplii, which occurred at different sampling depths and in different seasons, are considered to have been influenced by the occurrence of adults and changes in the hydrographic conditions, including temperature and water currents. In winter to early summer (January to June) nauplii of Oithona similis and Oithona atlantica, copepodites and adults, were abundant, while those of Oithona plumifera, and other species of Oithona and Oncaea showed a higher density between August and December.

During the spring season, when many fish larvae appeared, $O$. similis nauplii occurred at higher densities of more than $10^{5}$ indiv. $\mathrm{m}^{-3}$ in the upper layer $(0 \mathrm{~m}$ and $25 \mathrm{~m}$ depth) than those of $O$. atlantica. The weighted mean depth of $O$. atlantica nauplii was significantly deeper than that of $O$. similis nauplii. The respective vertical distributions of the nauplii of $O$. atlantica and $O$. similis were similar to the distributions of adults. Oithona similis nauplii are suggested to be a potentially important food item for fish larvae in spring because of their high density and similar vertical distribution to many fish larvae.
\end{abstract}

Key words: Oithona, Oncaea, seasonal abundance, Toyama Bay, vertical distribution

\section{Introduction}

The abundance of copepod nauplii encountered by early stage larvae of marine fish can significantly affect fish survival and development (Ikewaki \& Sawada 1991). Higher rates of larval development have been related to encountering high density patches of copepod nauplii (Oozeki \& Zenitani 1996). Various studies have concluded that increased rates of development in fish larvae lead to lower mortality from predation due to more rapid development of the sensory organs (e.g. Shepherd \& Cushing 1980). Because the overall density of copepod nauplii is low in the open ocean, the probability of the survival of fish larvae has been suggested to be associated with the distribution of high-density naupliar patches (Laurence 1974, O'Connell

\footnotetext{
* Corresponding author: Takashi Takahashi; E-mail, takutaku@jo-kan.or.jp
}

\& Raymond 1970, Sawada 1996).

Investigations of copepod nauplii, however, often fail to grasp the factors that influence their availability to fish larvae. The species composition of high densities of nauplii is clearly one of those factors. But, so far, the species of nauplii have not been determined, and, in most cases, high-density naupliar patches are only identified at the family or order level. The ecology of different species of nauplii within the same family varies greatly and requires detailed investigation. The species-level population and community structures of copepod nauplii within patches also require investigation. The relationship between the ecology of the species forming high-density naupliar patches and the factors affecting such patch occurrences also need to be examined.

Fish larvae, e.g. the Japanese sardine Sardinops melanostictus (Temminck \& Schlegel) and the anchovy Engraulis 
japonicus Temminck \& Schlegel are abundant in Toyama Bay, southern Sea of Japan, from May to July (Ito 1961, Hayashi 1990, Goto 1998). During the larval stage, sardines and anchovies prey mainly on Oithona and Oncaea nauplii (Hirakawa \& Goto 1996, Hirakawa et al. 1997). In Toyama Bay, sardines and anchovies are usually found at depths less than $25 \mathrm{~m}$ (Hayashi 1990). If the distribution depth of nauplii is species specific, we must clarify which species of nauplii are dominant at the depths where many of the fish larvae of commercial species are distributed.

Hirakawa et al. (2004) concluded that nauplii of Oithona similis Claus were the most dominant in their study based on the fact that adults of the species were abundant concurrently and the size of each naupliar stage matched that of this species. However, they did not identify the nauplii at the species level on the basis of morphological characteristics. Takahashi \& Uchiyama (2007) have recently described a method for identifying Oithona nauplii in Toyama Bay. They showed that $O$. similis is a major contributor to the high population density of Oithona nauplii. However, Takahashi \& Uchiyama (2007) did not investigate the vertical distributions of nauplii of other species. In this paper we examine the vertical distributions of nauplii, and copepodite species of Oithona, Oncaea and others. We also discuss the factors that influence the characteristic vertical distributions of nauplii, and their availability as food for fish larvae.

\section{Materials and Methods}

Six naupliar (N1-6) and six copepodite (C1-6) stages of Oithona and Oncaea were collected in the central region of Toyama Bay (Stn. 8) from January 1997 to December 1999 (Fig. 1). Samples were taken once or twice per month. Water samples were taken with van Dorn bottles $(10 \mathrm{~L})$ at depths of $0 \mathrm{~m}, 25 \mathrm{~m}$ and $50 \mathrm{~m}$, filtered through a $0.02 \mathrm{~mm}$ mesh net and fixed in 3-5\% formaldehyde. High densities of copepod nauplii were found at depths of less than $50 \mathrm{~m}$ (Sawada 1996, Hirakawa et al. 2004).

All Oithona copepodite stages were identified at the species level and counted for each entire sample (not split). Oithona and Oncaea adults (C6) and copepodites (inferred from the morphological characteristics of the adult stage) were identified to the species level according to keys to species provided by Ito (1997) and Nishida (1997). The cold-water and warm-water species were separated by their geographic distribution. The nauplius stages were identified and counted under a microscope in $1 / 15$ to $1 / 20$ aliquots of each sample. Nauplii for each genus were counted and identified using a key developed by Koga (1984). Nauplii of Oithona similis, Oithona atlantica Farran, Oithona plumifera Baird, and the other Oithona spp. and Oncaea spp. were differentiated according to the method of Takahashi \& Uchiyama (2007). Small nauplii, with an N1-stage body length of $<0.1 \mathrm{~mm}$ (Oithona nana Giesbrecht, Oithona davisae Ferrari \& Orsi or Oithona rigida Gies-

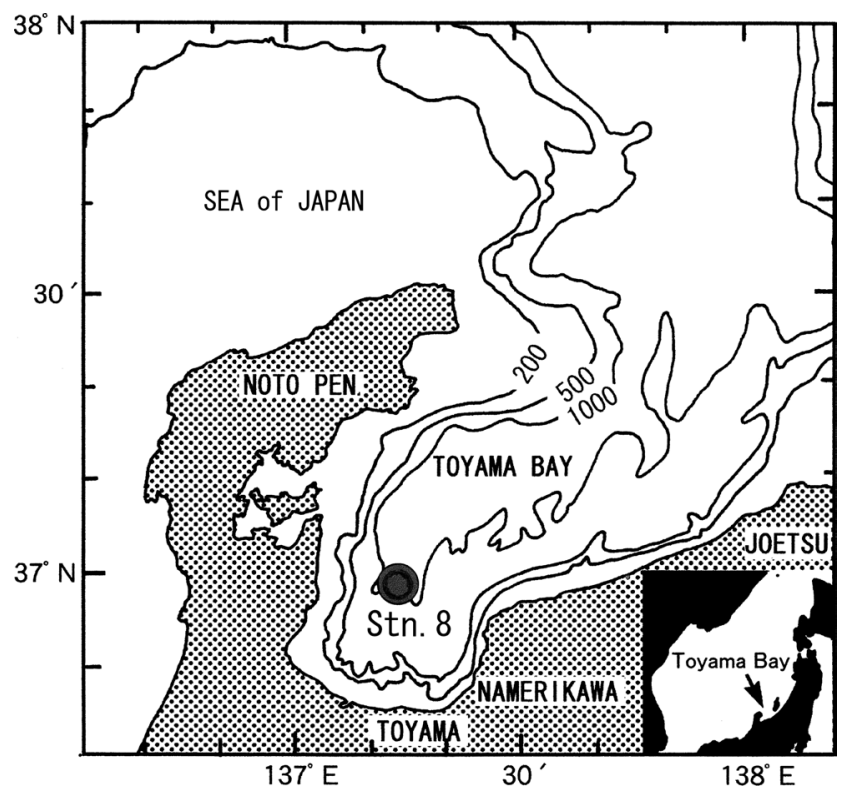

Fig. 1. Map showing the sampling site (O) for this study in Toyama Bay, Sea of Japan.

brecht) were grouped together as congeners. It was very difficult to distinguish between nauplii of the genus Oncaea at species level, so those nauplii with a pair of long second segment antennules (Koga 1984) were identified as Oncaea nauplii.

The weighted mean depth (WMD) of nauplii was calculated according to the method outlined by Frost \& Bollens (1992); that is, $W M D=\left(\sum n_{\mathrm{s}} d_{\mathrm{s}}\right) / \sum n_{\mathrm{s}}$, where $d_{\mathrm{s}}$ is the sampling depth and $n_{\mathrm{s}}$ is the density (indiv. $\mathrm{m}^{-3}$ ) of the species s. Differences in mean $W M D$ were compared using the Wilcoxon signed ranks test.

From January 1997 to October 1998, vertical profiles of temperature and salinity at Stn. 8 in Toyama Bay were measured during sampling using a CTD (MK3B, Neil Brown, SBE911, Seabird Co., Ltd.), and surface water salinity was measured with a salinometer (601MKIII, Yeo-kal, Autosal, Guildline Co., Ltd.). Over this period, chlorophyll- $a$ in water samples from depths of $0 \mathrm{~m}, 25 \mathrm{~m}$ and $50 \mathrm{~m}$ was measured using the fluorescence method (Parsons et al. 1984). To observe large changes in the submarine climate, we investigated environmental factors between $0 \mathrm{~m}$ and $300 \mathrm{~m}$. From November 1998 to December 1999, vertical profiles of temperature, salinity and fluorescence were measured simultaneously with a CTD (ACL200DK, Alec Co., Ltd.).

\section{Results}

\section{Hydrography}

From March to April during the three years of investigation, the lowest water temperature in the upper $50 \mathrm{~m}$ was $10^{\circ} \mathrm{C}$ (Fig. 2, upper panel). Each year, vertical mixing occurred in the upper $150 \mathrm{~m}$ from February to May and the 
Temp. $\left({ }^{\circ} \mathrm{C}\right)$
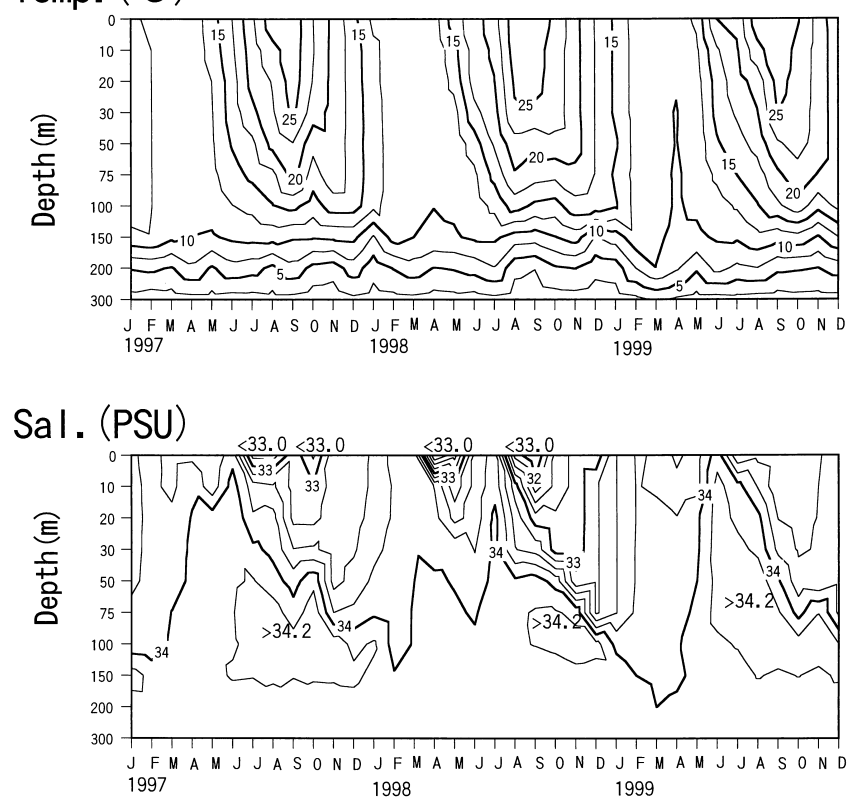

Chlorophyl I-a

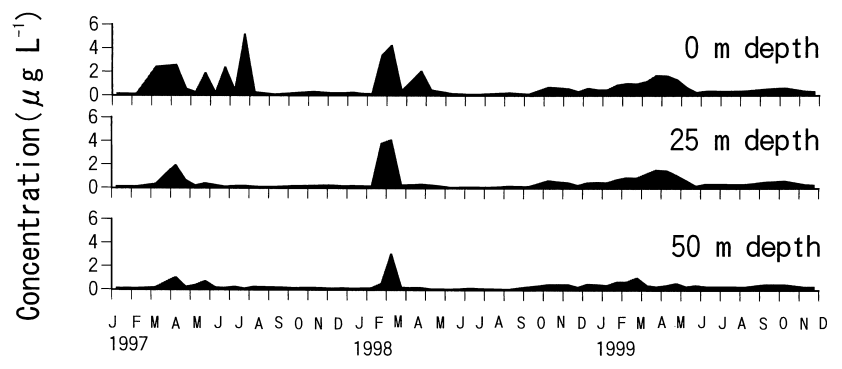

Fig. 2. Seasonal variations in temperature (upper), salinity (middle) and chlorophyll- $a$ concentration (lower) at Stn. 8 in Toyama Bay (adapted from Takahashi \& Uchiyama 2007).

concentration of chlorophyll- $a$ increased to more than $1.0-4.0 \mu \mathrm{g} \mathrm{L}^{-1}$ from February to May (Fig. 2, lower panel).

After May, water temperatures increased gradually. Surface water salinities were observed to be less than 33 PSU in May, June and August-October in 1997 and 1998 (Fig. 2, middle panel), which indicates the possible intrusion of river water between May and July (Nagata \& Nakura 1993) or surface water of the Tsushima Warm Current (TWC) in August (Ogawa 1983). At this time, the chlorophyll- $a$ concentration decreased rapidly to below $0.5 \mu \mathrm{g} \mathrm{L}^{-1}$. However, in 1997, a higher concentration of chlorophyll- $a(>1.0 \mu \mathrm{g}$ $\left.\mathrm{L}^{-1}\right)$ was observed at the surface $(0 \mathrm{~m})$ after May, with the highest value $\left(5.1 \mu \mathrm{g} \mathrm{L}^{-1}\right)$ recorded in mid-July. During this season (mid-July) in 1997, water of low salinity (less than 33 PSU) was observed at the surface $(0-5 \mathrm{~m})$, which indicates the possible intrusion of river water from mid-June to July.

The water column became thermally stratified during summer. In August, the highest surface water temperature recorded was $28^{\circ} \mathrm{C}$, and the water temperatures decreased gradually after September. Salinities that were consistently

\section{Total density}
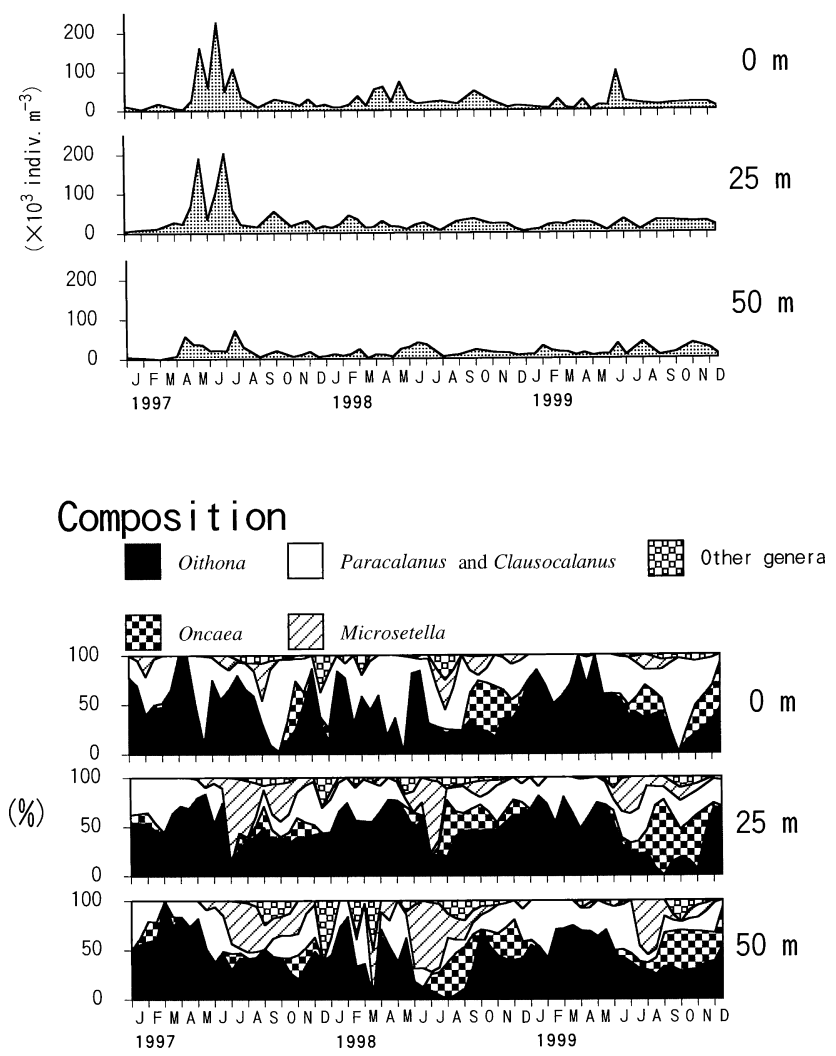

Fig. 3. Seasonal variations in the total density of copepod nauplii (upper) and the genus composition (lower) at depths of 0, 25 and $50 \mathrm{~m}$ in Toyama Bay from January 1997 to December 1999.

greater than 34.2 PSU were observed at a depth of 10-100 $\mathrm{m}$ every year from June-August to December-January, which indicates the possible intrusion of core water from the TWC.

Seasonal changes in abundance and composition of nauplii of various genera

At $0 \mathrm{~m}$ the total copepod naupliar abundance increased from April to June each year, and the highest total abundance $\left(230 \times 10^{3}\right.$ indiv. $\left.\mathrm{m}^{-3}\right)$ was recorded in June 1997 (Fig. 3 upper panel). Total naupliar abundance increased slightly from April to May in 1998 and 1999 but was lower than the 1997 value, with a maximum density of $80-100 \times 10^{3}$ indiv. $\mathrm{m}^{-3}$. It decreased to $20-30 \times 10^{3}$ indiv. $\mathrm{m}^{-3}$ after August in each year. Oithona nauplii were the most important component throughout the three years, and $55 \%$ of the highest total abundance in June 1997 consisted of nauplii of this genus (Fig. 3 lower panel). In May and September to October of almost every year, Paracalanus and Clausocalanus were also major naupliar components.

At a depth of $25 \mathrm{~m}$ the total copepod naupliar abundance increased in May and July 1997, with $190 \times 10^{3}$ indiv. $\mathrm{m}^{-3}$ in May and $198 \times 10^{3}$ indiv. $\mathrm{m}^{-3}$ in July (Fig. 3 upper panel). Oithona nauplii constituted $84 \%$ of the total in May (Fig. 3 
lower panel). The total naupliar abundance did not increase during spring in 1998 and 1999. Between July and November in each year, Oncaea was a major naupliar component (13-77\%). In June and July of almost every year, Microsetella was a major naupliar component (37-89\%).

At a depth of $50 \mathrm{~m}$ the total copepod naupliar abundance increased from April to July 1997 (Fig. 3 upper panel). The second highest total density of nauplii $\left(75 \times 10^{3}\right.$ indiv. $\left.\mathrm{m}^{-3}\right)$ occurred in April and the highest $\left(81 \times 10^{3}\right.$ indiv. $\left.\mathrm{m}^{-3}\right)$ in July 1997. However, these higher densities were less than those recorded at $0 \mathrm{~m}$ and $25 \mathrm{~m}$. Oithona nauplii constituted $42 \%$ of the highest density and $78 \%$ of the second highest (Fig. 3 lower panel). Oncaea and Microsetella were major naupliar components in the same months as at $25 \mathrm{~m}$ depth.

The highest total naupliar densities at $0 \mathrm{~m}$ and $25 \mathrm{~m}$ were greater than at $50 \mathrm{~m}$, with the greatest density of Oithona nauplii $\left(160 \times 10^{3}\right.$ indiv. $\left.\mathrm{m}^{-3}\right)$ being observed at $25 \mathrm{~m}$ in 1997. However, in 1998 and 1999 the greatest density $\left(24-60 \times 10^{3}\right.$ indiv. $\left.\mathrm{m}^{-3}\right)$ decreased. Oithona and Oncaea nauplii, which were examined in detail in this study, were the most important component, constituting more than $50 \%$ of the mean total naupliar density per sample throughout the three consecutive years $(50 \%$ at $0 \mathrm{~m}, 57 \%$ at $25 \mathrm{~m}$ and $55 \%$ at $50 \mathrm{~m}$; Fig. 3 , lower panel).

\section{Seasonal changes in abundance and composition of nau- pliar and copepodite stages of each species}

The maximum density of nauplii was almost ten times the density of copepodites and adults for each species over the three years.

Oithona similis. The nauplii occurred almost continuously throughout the year, except in August and September (Fig. 4). The nauplii had higher density peaks at $0 \mathrm{~m}$ and 25 $\mathrm{m}$ than at $50 \mathrm{~m}$ in April and June, with the greatest value (over $10^{5}$ indiv. $\mathrm{m}^{-3}$ ) in June 1997 . At $0 \mathrm{~m}$ and $25 \mathrm{~m}$ depth, Oithona similis nauplii were the main naupliar component during the whole survey period, comprising $>50 \%(0 \mathrm{~m})$ and ca. $33 \%(25 \mathrm{~m})$ of the total density of Oithona and Oncaea nauplii (Fig. 5). In 1997, at $0 \mathrm{~m}, 93 \%$ of the greatest naupliar abundance was made up of $O$. similis nauplii. Copepodite and adult densities of this species were greater at $0 \mathrm{~m}$ and $25 \mathrm{~m}$ than at $50 \mathrm{~m}$ as was also the case for nauplii (Fig. 4). Increases in the density of $O$. similis copepodites and adults occurred in the same seasons as those of nauplii. The greatest densities of $O$. similis copepodites and adults $\left(13-16 \times 10^{3}\right.$ indiv. $\left.\mathrm{m}^{-3}\right)$ were observed in 1998 , although for nauplii it was in 1997.

Oithona atlantica. The nauplii had higher density peaks at $25 \mathrm{~m}$ and $50 \mathrm{~m}$ than at $0 \mathrm{~m}$ (Fig. 4), with the highest density $\left(10-60 \times 10^{3}\right.$ indiv. $\left.\mathrm{m}^{-3}\right)$ from February to May. After

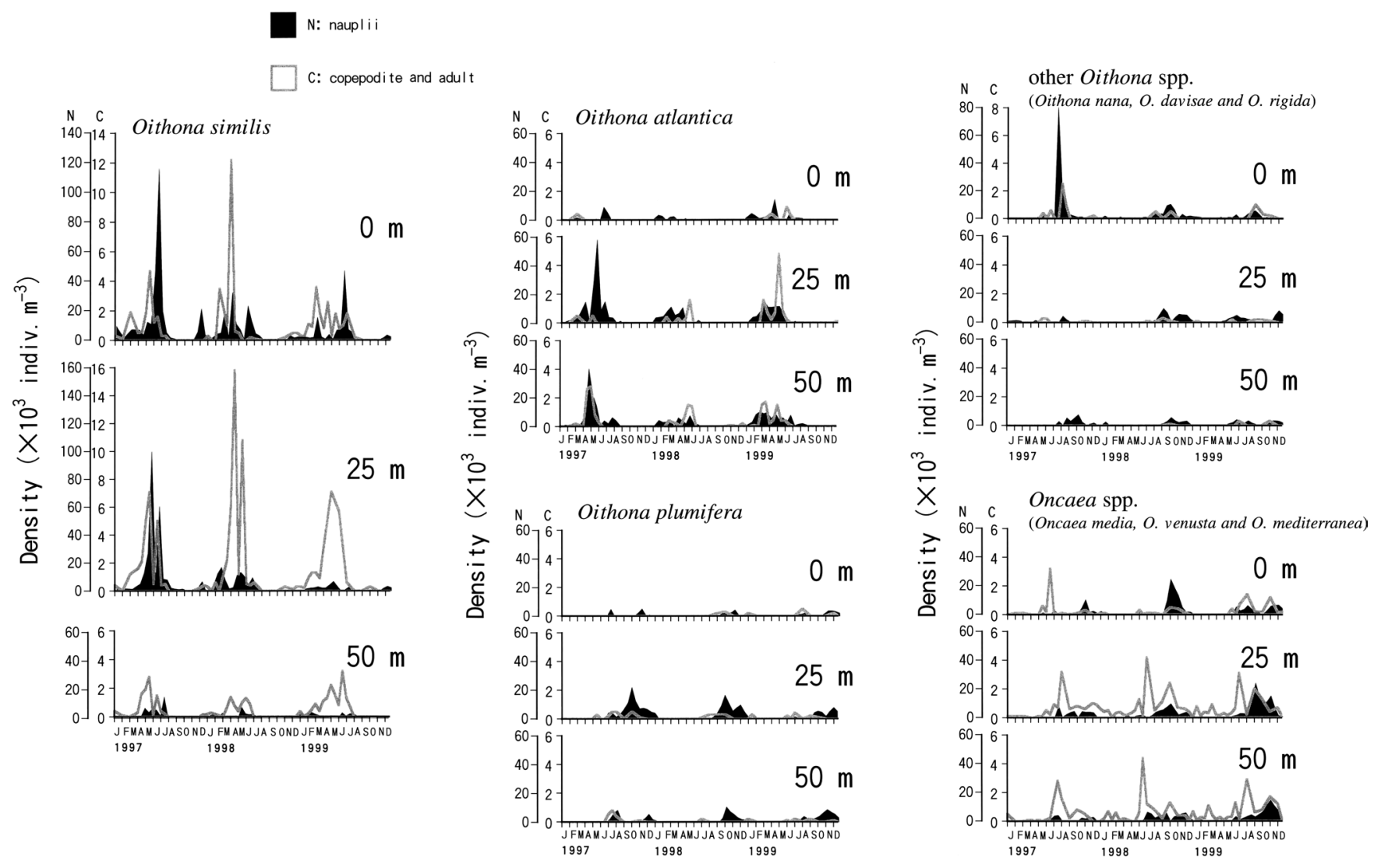

Fig. 4. Seasonal variations in the densities of nauplii, copepodites and adults of five taxa at depths of 0, 25 and $50 \mathrm{~m}$ in Toyama Bay from January 1997 to December 1999. 
June, however, the density decreased in all three years. Between December and July, $O$. atlantica nauplii were the main naupliar component at $25 \mathrm{~m}$ and $50 \mathrm{~m}$ (Fig. 5). At 25 $\mathrm{m}, O$. atlantica nauplii were the second most abundant taxonomic component, constituting $30 \%$, and were the most dominant at $50 \mathrm{~m}$, constituting approximately $34 \%$ of the total density of Oithona and Oncaea nauplii over the three consecutive years. $O$. atlantica copepodites and adults were found in the same season and at the same depth as nauplii (Fig. 4). The greatest density of $O$. atlantica copepodites and adults $\left(6 \times 10^{3}\right.$ indiv. $\left.\mathrm{m}^{-3}\right)$ was observed at $25 \mathrm{~m}$ in 1999, whereas the greatest density of nauplii was observed in 1997.

Oithona plumifera. The naupliar abundance was greatest at a depth of $25 \mathrm{~m}$ (Fig. 4), increasing from June to reach a maximum $\left(10-25 \times 10^{3}\right.$ indiv. $\left.\mathrm{m}^{-3}\right)$ between September and October each year. The nauplii of this species were not observed from January to May, when $O$. atlantica nauplii were abundant. The nauplii of these two species appeared simultaneously between June and August, and in December. At depths of $25 \mathrm{~m}$ and $50 \mathrm{~m}$, from August to November, $O$. plumifera were the main component of total Oithona and Oncaea nauplii (Fig. 5). O. plumifera copepodites and adults occurred in the same season as the nauplii (Fig. 4), but their greatest densities were lower than those of other Oithona species.

Other Oithona spp. Naupliar abundance was greatest at 0 m (Fig. 4). In 1997, the naupliar abundance rapidly increased from early July to reach a maximum $\left(80 \times 10^{3}\right.$ indiv. $\mathrm{m}^{-3}$ ) in the middle of July. This maximum naupliar density was mainly comprised of Oithona nana. Maximum densities in 1998 and 1999 were lower than in 1997, although the seasonal occurrences were the same. At $0 \mathrm{~m}$, nauplii of other Oithona species were most dominant between August and September in each year (Fig. 5). At $25 \mathrm{~m}$ and $50 \mathrm{~m}$, other Oithona species were sometimes the main component from August to November. In this study, the other Oithona copepodites and adults identified were from three species: Oithona davisae, $O$. nana, and $O$. rigida. The copepodites and adults of these other Oithona species occurred in the same seasons as the nauplii (Fig. 4).

Oncaea spp. The naupliar densities of Oncaea spp. increased from June to August-November, when the maximum density $\left(10-25 \times 10^{3}\right.$ indiv. $\left.\mathrm{m}^{-3}\right)$ was recorded, and then decreased after December (Fig. 4). Oncaea spp. were the main component from August to November at each depth (Fig. 5). Nauplii of Oncaea spp. were the second most important taxon, constituting $20 \%$ at $0 \mathrm{~m}$ and $21 \%$ at $25 \mathrm{~m}$ of the total Oithona and Oncaea nauplii. In this study, the Oncaea copepodites and adults were comprised of three species: Oncaea media Giesbrecht, Oncaea venusta Philippi and Oncaea mediterranea (Claus). Oncaea copepodites and adults occurred throughout the year, with the greatest density $\left(3-4 \times 10^{3}\right.$ indiv. $\left.\mathrm{m}^{-3}\right)$ observed in the same season as the nauplii (Fig. 4).
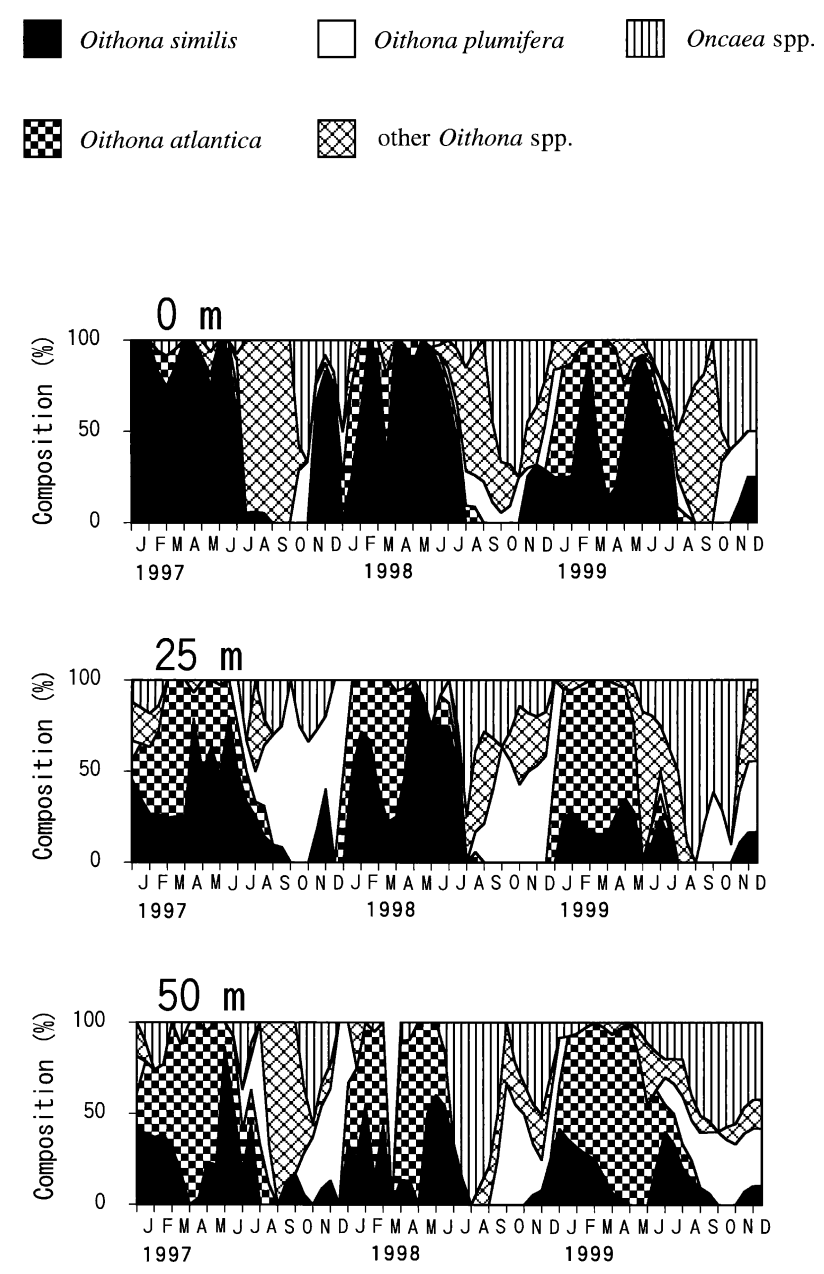

Fig. 5. Seasonal variations in the composition of nauplii of five taxa at depths of 0,25 and $50 \mathrm{~m}$ in Toyama Bay from January 1997 to December 1999.

\section{Vertical distribution of Oithona and Oncaea nauplii}

From February to July, the $W M D$ of $O$. atlantica nauplii was below $25 \mathrm{~m}(25.2-42.5 \mathrm{~m}$, average $30.4 \mathrm{~m})$, while that of $O$. similis nauplii was above $25 \mathrm{~m}(6.5-24.0 \mathrm{~m}$, average $16.7 \mathrm{~m}$ ) (Fig. 6). The $W M D$ s of $O$. atlantica and $O$. similis nauplii were significantly different (Wilcoxon signed ranks test: $p<0.01)$. The $W M D$ s of the warm-water $O$. plumifera and Oncaea nauplii were concentrated at about $25 \mathrm{~m}(O$. plumifera: $23.9-31.8 \mathrm{~m}$, average $28.9 \mathrm{~m}$, Oncaea: $16.5-29.4$ $\mathrm{m}$, average $23.6 \mathrm{~m}$ ). The $W M D \mathrm{~s}$ of the nauplii of these two taxa were not significantly different (Wilcoxon signed ranks test: $p>0.05$ ).

\section{Discussion}

\section{Seasonal changes in abundance}

In Toyama Bay, we found that Oithona and Oncaea nauplii were a significant proportion of the total copepod nauplii. Oithona and Oncaea species have a worldwide distrib- 

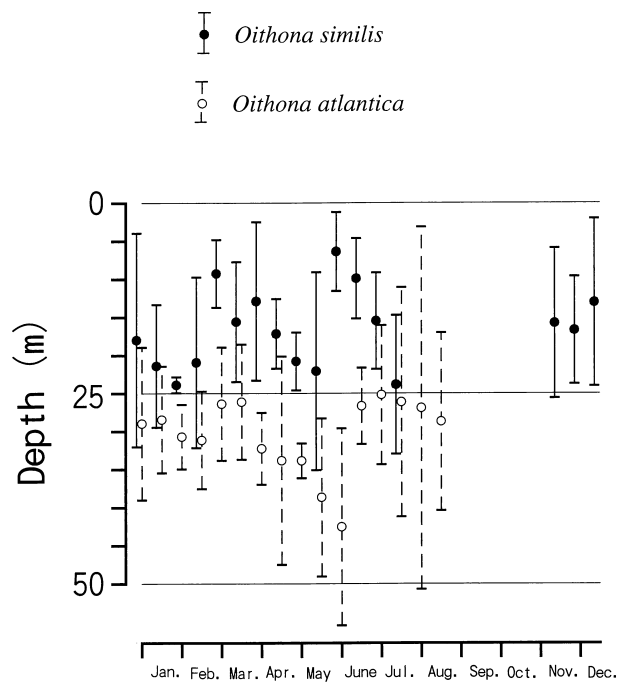

$\stackrel{\top}{\triangle}$ Oithona plumifera

I Oncaea spp.

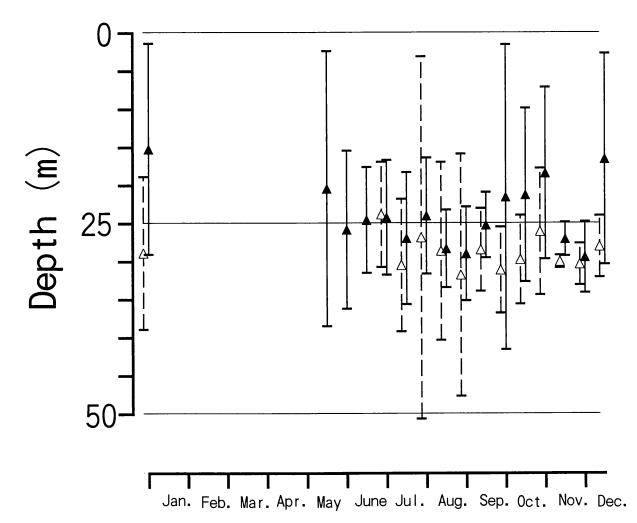

Fig. 6. Seasonal changes in the weighted mean depths (WMDs) of the nauplii of four taxa (Oithona atlantica, O. similis, O. plumifera and Oncaea spp.) in Toyama Bay from January 1997 to December 1999. Vertical lines represent \pm 1 SD.

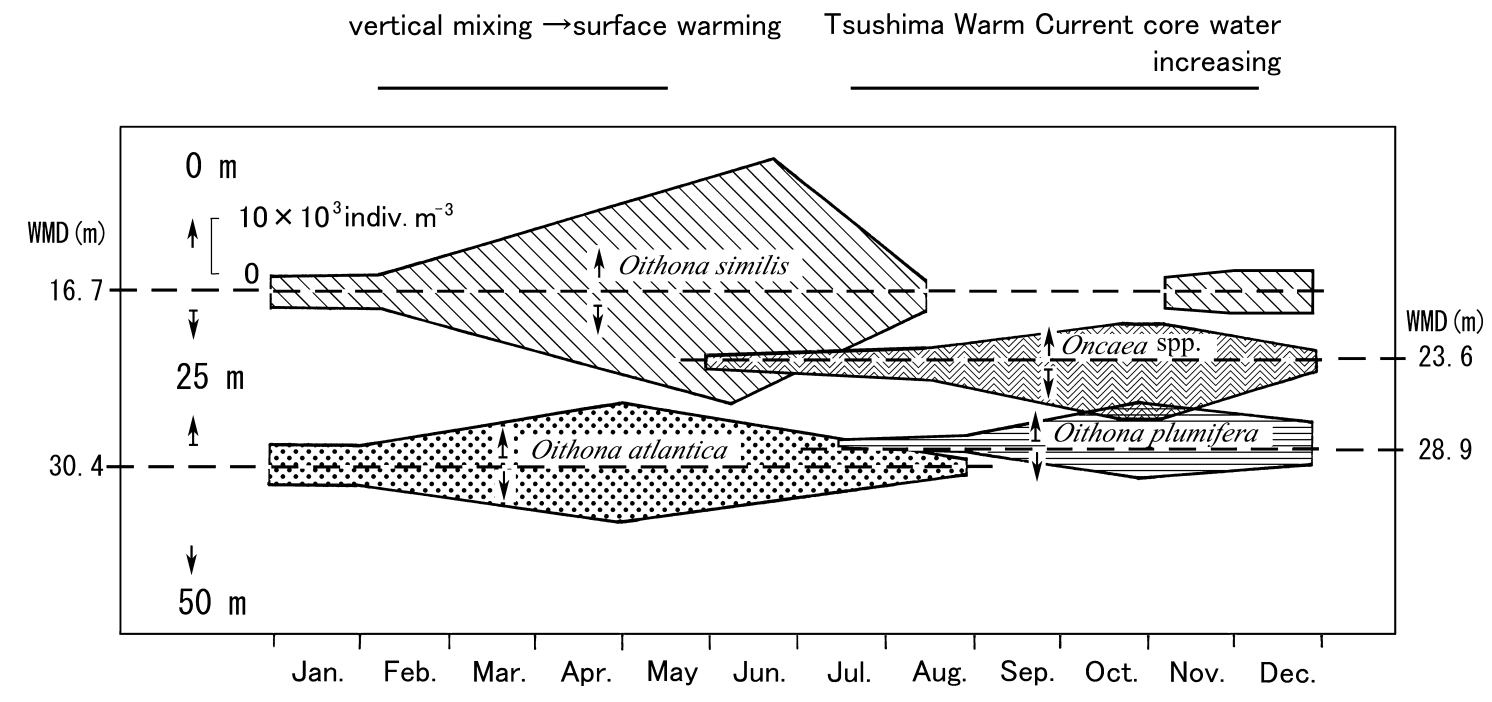

Fig. 7. Schematic diagram showing seasonal occurrence (averaged over three years) of the nauplii of three Oithona species and Oncaea nauplii in the layers where they were the main naupliar component (in the direction of the arrows) in Toyama Bay. Horizontal broken lines show average $W M D$ s for each species. Top bars show the water mass characteristics.

ution (Paffenhöfer 1993), and the genus Oithona has already received much attention (Gallienne \& Robins 2001, Castellani et al. 2005a). In this study, Oithona and Oncaea nauplii occurred over the three years, constituting more than $50 \%$ of the average total copepod naupliar density.

Figure 7 shows the seasonal occurrence (averaged over three years) of the three nauplii of the Oithona species and of Oncaea nauplii in the layers with high naupliar densities (in the first and second highest density layers, with an average naupliar density of $>1 \times 10^{3}$ indiv. $\mathrm{m}^{-3}$ ). Oithona similis and Oithona atlantica nauplii were abundant between January and July, during which time the vertically mixed water column gradually became vertically stratified. There is a clear segregation in the vertical distribution of these two cold-water naupliar species in Toyama Bay: O. similis and
O. atlantica occurred in the region of $0-25 \mathrm{~m}$ and $25-50 \mathrm{~m}$, respectively. Oithona plumifera and Oncaea nauplii were abundant between August and December when an intrusion of the TWC and high water temperatures occurred (Naganuma 2000). Hirakawa (1995) noted the influence of temperature on reproduction in Oncaea venusta, which reproduces actively at high temperatures $\left(>20-25^{\circ} \mathrm{C}\right)$, but not at low temperatures $\left(<15^{\circ} \mathrm{C}\right)$. Increasing temperatures cause nauplii of warm-water species to appear in abundance.

Hirakawa et al. (2004) suggested that low salinity surface waters in the Sea of Japan in May and June were due to the in-flow of river water, which led to high chlorophyll- $a$ concentrations and high densities of $O$. similis nauplii. The results of this study did not confirm the statistically signifi- 
cant relationship between low salinity and either the high density of nauplii or the high concentration of chlorophyll$a$ (regression analysis $p>0.05$ ). However, the maximum density of $O$. similis nauplii coincided with the highest chlorophyll- $a$ concentration from June to July 1997 . The increased concentration of chlorophyll- $a$ has been reported to be caused by an increase in the density of flagellates, which are an appropriately sized food for $O$. similis nauplii in Toyama Bay (Taniguchi et al. 1997, Hirakawa et al. 2004). One of the reasons for the high density of $O$. similis may have been an increased density of flagellates, a food source for nauplii, which is suggested by the observed increase in chlorophyll- $a$ concentration. However, we do not have any data on the cell density of flagellates per se.

Oithona similis is regarded as the most abundant and ubiquitous species of copepod in cold-water marine environments (e.g. Castellani et al. 2005a). The reason for its success is its continuous and constant rate of egg production throughout the year (Fransz \& Gonzalez 1995, Castellani et al. 2005b), and its high rate of egg hatching in cold water (Nielsen et al. 2002). Based on laboratory experiments, hatching time in $O$. similis has been found to decrease with increasing water temperature between -1 and $20.5^{\circ} \mathrm{C}$ (Nielsen et al. 2002). In mid-June in Toyama Bay, the average surface water temperature recorded was about $20^{\circ} \mathrm{C}\left(19.8-20.3^{\circ} \mathrm{C}\right.$ in $\left.1997-1999\right)$. We propose that the density of $O$. similis nauplii was higher in mid-June in Toyama Bay because the life cycle progressed most rapidly during this period due to the fast growth of the nauplii.

\section{Vertical distribution}

Our study showed that the $W M D$ of $O$. atlantica nauplii was greater than that of $O$. similis nauplii. Hirakawa et al. (2004) showed that the abundance of larger nauplii (body length $>0.2 \mathrm{~mm}$ ) increased in layers below $50 \mathrm{~m}$ in unspecified nauplii from the two species $O$. atlantica and $O$. similis in Toyama Bay. Our conclusion from the present study is that the small $O$. similis nauplii (N1-N5 body length $<0.2 \mathrm{~mm}$ ) were mainly distributed in the $0-25 \mathrm{~m}$ zone, whereas the larger $O$. atlantica nauplii (N3-N6 body length $>0.2 \mathrm{~mm}$ ), were more abundantly distributed in the $25-50$ $\mathrm{m}$ zone.

Morphologically similar Oithona adults that thrive in the same area tend to have different vertical distributions (Nishida \& Marumo 1982). We propose that the same is true for Oithona nauplii, based on the observation that their distribution depth is the same as that of the adult females. It is likely that the vertical distribution of nauplii is influenced by the distribution of the adults for a number of reasons. For example, Oithona species are all egg-carrying and Oithona adults do not follow diel vertical migration patterns for reproduction (Zalkina 1970, Boxshall 1977, Ueda 1987). In neritic copepod nauplii, the vertical distribution changes seasonally, and this may be associated with breeding cycles and changing depth preferences of different stages in the life cycle (Sekiguchi 1985, Ueda 1987, Uye et al. 1990). For Oithona, the adult stage of O. atlantica was primarily distributed in layers deeper than $500 \mathrm{~m}$ from summer to winter but was recorded at a depth of $60 \mathrm{~m}$ in March, which suggests an ontogenetic vertical migration (Takahashi \& Hirakawa 2001). In this study, we found that the abundance of $O$. atlantica nauplii increased from February to April in the shallow layer $(0-50 \mathrm{~m}$ depth), which also suggests ontogenetic migration of adult females. Sawada (1996) described the vertical distribution of copepod nauplii in Wakasa Bay: Oithona nauplii were distributed above a depth of $10 \mathrm{~m}$ and Microsetella nauplii were distributed at depths greater than $10 \mathrm{~m}$. These generic differences in depth distribution indicate different optimal water temperatures for each genus. Oithona similis maintained a similar vertical distribution during both the day and night (with a median depth of $30 \mathrm{~m}$ ) throughout the copepodite and adult stages in Fladen Ground, Norway (Eiane \& Ohman 2004). In Toyama Bay, the maximum density of $O$. similis adults occurred at 10-30 $\mathrm{m}$ in May (Hirakawa et al. 2004), a similar depth to that observed for $O$. similis nauplii $(0-25 \mathrm{~m})$ in this study. The vertical distributions of $O$. atlantica and $O$. similis adults were similar to those of the nauplii of the same species, in the present study.

In Toyama Bay, the Japanese sardine, anchovy and $H y$ porhamphus sajori (Temminck \& Schlegel) larvae which prey mainly on Oithona nauplii are distributed between $0 \mathrm{~m}$ and $25 \mathrm{~m}$ (Hirakawa \& Goto 1996, Hirakawa et al. 1997, Oya et al. 2002). These fish larvae occur in Toyama Bay from May to July when $O$. similis is at the maximum density. During this period, larvae and eggs of these fish species are distributed between $0 \mathrm{~m}$ and $25 \mathrm{~m}$, as are $O$. similis nauplii. We believe therefore that $O$. similis nauplii may be a good food source for these fish larvae, owing to their high density of occurrence and their similar vertical distributions, and this ensures a high likelihood of fish larvae encountering them as a potential food source.

\section{Acknowledgments}

We thank the captain and crew members of the RV 'Tateyama-Maru', Toyama Prefectural Fisheries Experimental Station. We also wish to express our thanks to Dr. A. Ohno for his critical reading of the manuscript, and to Drs. K. Hirakawa and S. D. Guzman for their encouragement and advice. Thanks are extended to the editor and two anonymous reviewers for many critical and constructive comments.

\section{References}

Boxshall GA (1977) The depth distributions and community organizations of the planktonic cyclopoids (Crustacea: Copepoda) of the Cape Verde Islands region. J Mar Biol Assoc UK 57: 543-568.

Castellani C, Robinson C, Smith T, Lampitt RS (2005a) Tempera- 
ture affects respiration rate of Oithona similis. Mar Ecol Prog Ser 285: 129-135.

Castellani C, Irigoien X, Harris RP, Lampitt RS (2005b) Feeding and egg production of Oithona similis in the North Atlantic. Mar Ecol Prog Ser 288: 173-182.

Eiane K, Ohman MD (2004) Stage-specific mortality of Calanus finmarchicus, Pseudocalanus elongatus and Oithona similis on Fladen Ground, North Sea, during a spring bloom. Mar Ecol Prog Ser 268: 183-193.

Fransz HG, Gonzalez SR (1995) The production of Oithona similis (Copepoda: Cyclopoida) in the Southern Ocean. ICES J Mar Sci 52: 549-555.

Frost BW, Bollens SM (1992) Variability of diel vertical migration in the marine planktonic copepod Pseudocalanus newmani in relation to its predators. Can J Fish Aquat Sci 49: 1137-1141.

Gallienne GP, Robins DB (2001) Is Oithona the most important copepod in the world's oceans? J Plankton Res 23: 1421-1432.

Goto T (1998) Abundance and distribution on the egg of the sardine, Sardinops melanostictus, in the Japan Sea during spring, 1979-1994. Bull Japan Sea Natl Fish Res Inst 48: 51-60. (in Japanese with English abstract)

Hayashi S (1990) Seasonal abundance and vertical distribution of fish eggs and larvae in Toyama Bay, the Japan Sea. Bull Toyama Pref Fish Exp Stn 2: 1-17. (in Japanese)

Hirakawa K (1995) Effects of temperature on egg production of a warm-water copepod Oncaea venusta PHILIPPI (Poecilostomatoida). Bull Japan Sea Natl Fish Res Inst 45: 39-45. (in Japanese with English abstract)

Hirakawa K, Goto T (1996) Diet of larval sardine, Sardinops melanostictus in Toyama Bay, southern Japan Sea. Bull Japan Sea Natl Fish Res Inst 46: 65-75. (in Japanese with English abstract)

Hirakawa K, Goto T, Hirai M (1997) Diet composition and prey size of larval anchovy, Engraulis japonicus, in Toyama Bay, southern Japan Sea. Japan Sea Natl Fish Res Inst 47: 67-78.

Hirakawa K, Goto T, Hirai M (2004) Distribution of oithonid copepods as food for larvae of Japanese sardine and anchovy in Toyama Bay, southern Japan Sea. Bull Plankton Soc Jpn 51: 1-12. (in Japanese with English abstract)

Ikewaki Y, Sawada Y (1991) Food habits of marine fish larvae. In: Early Development in Fishes (ed Tanaka M), Fisheries Science Series 83. Koseisha-Koseikaku, Tokyo, pp. 86-104. (in Japanese)

Ito H (1997) Oncaeidae. In: An Illustrated Guide to Marine Plankton in Japan (eds Chihara M, Murano M). Tokai University Press, Tokyo, pp. 978-988. (in Japanese)

Ito S (1961) Fish biology of the sardine, Sardinops melanosticta (T\&S), in the waters around Japan. Bull Japan Sea Reg Fish Res Inst 9: 1-227. (in Japanese with English abstract)

Koga F (1984) Morphology, ecology, classification and specialization of copepods nauplius. Bull Nansei Reg Fish Res Lab 16: 95-229. (in Japanese with English abstract)

Laurence GC (1974) Growth and survival of haddock (Melanogrammus aeglefinus) larvae in relation to planktonic prey concentration. J Fish Res Board Can 31: 1415-1419.

Naganuma K (2000) The Sea of Japan as the natural environment of marine organisms. Bull Japan Sea Natl Fish Res Inst 50: 1-42. (in Japanese with English abstract)
Nagata H, Nakura N (1993) Seasonal changes of river discharge and chlorophyll- $a$ concentration in Toyama Bay, southern Japan Sea. Bull Japan Sea Natl Fish Res Inst 43: 55-68. (in Japanese with English abstract)

Nielsen TG, Moller EF, Satapoomin S, Ringuette M, Hopcroft PR (2002) Egg hatching rate of the cyclopoid copepod Oithona similis in arctic and temperate waters. Mar Ecol Prog Ser 236: 301-306.

Nishida S (1997) Cyclopoida. In: An Illustrated Guide to Marine Plankton in Japan (eds Chihara M, Murano M). Tokai University Press, Tokyo, pp. 935-951. (in Japanese)

Nishida S, Marumo R (1982) Vertical distribution of cyclopoid copepods of the family Oithonidae in the western Pacific and eastern Indian Oceans. Bull Plankton Soc Jpn 29: 99-118.

O'Connell CP, Raymond P (1970) The effect of food density on survival and growth of early post yolk-sac larva of the northern anchovy (Engraulis mordax Girard) in the laboratory. J Exp Mar Biol Ecol 5: 187-197.

Ogawa Y (1983) Seasonal changes in temperature and salinity of water flowing into the Japan Sea through the Tsushima Straits. Bull Jpn Soc Fish Oceanogr 43: 1-8. (in Japanese with English abstract)

Oozeki Y, Zenitani H (1996) Factors affecting the recent growth of Japanese sardine (Sardinops melanostictus) in the Kuroshio Current. In: Survival Strategies in Early Life Stages of Marine Resources (eds Watanabe Y, Yamashita Y, Oozeki Y). A A Balkema, Rotterdam. pp. 95-104.

Oya F, Tsuji T, Fujiwara S (2002) Relative growth and feeding habits of halfbeak, Hyporhamphus sajori, larvae and juveniles in Toyama Bay of the Japan Sea. Aquacult Sci (Suisanzoshoku) 50: 47-54.

Paffenhöfer GA (1993) On the ecology of marine cyclopoid copepods (Crustacea, Copepoda, Cyclopoida). J Plankton Res 15: 37-55.

Parsons TR, Maita Y, Lalli CM (1984) A manual of chemical and biological methods for seawater analysis. Pergamon Press, Oxford, $173 \mathrm{pp}$.

Sawada Y (1996) High density layer formation of Copepoda nauplii in the western Wakasa Bay. Bull Jpn Soc Fish Oceanogr 54: 341-351. (in Japanese with English abstract)

Sekiguchi H (1985) Biology of cladocerans and copepods in Ise Bay-2, vertical distribution of neritic copepods in relation to their life histories. Bull Fac Fish, Mie Univ 12: 1-12.

Shepherd J, Cushing DH (1980) A mechanism for density dependent survival of larval fish as the basis of stock recruitment relationship. J Cons int Explor Mer 39: 160-167.

Takahashi T, Hirakawa K (2001) Day-night vertical distributions of the winter and spring copepod assemblage in Toyama Bay, southern Japan Sea, with special reference to Metridia pacifica and Oithona atlantica. Bull Plankton Soc Jpn 48: 1-13. (in Japanese with English abstract)

Taniguchi A, Nakashima Y, Suzuki T, Hirakawa K, Imamura A, Ikeda T (1997) Seasonal variations in the phytoplankton assembly in Toyama Bay, southern Japan Sea. Bull Japan Sea Natl Fish Res Inst 47: 33-55. (in Japanese with English abstract)

Takahashi T, Uchiyama I (2007) Morphology of the naupliar stages of some Oithona species (Copepoda: Cyclopoida) occurring in Toyama Bay, southern Japan Sea. Plankton Benthos Res 


\section{2: 12-27.}

Ueda H (1987) Small-scale ontogenetic and diel vertical distributions of neritic copepods in Maizuru Bay, Japan. Mar Ecol Prog Ser 35: 65-73.

Uye S, Huang C, Onbe T (1990) Ontogenetic diel vertical migra- tion of planktonic copepod Calanus sinicus in the Inland Sea of Japan. Mar Biol 104: 389-396.

Zalkina AV (1970) Vertical distribution and diurnal migration of some Cyclopoida (Copepoda) in the tropical region of the Pacific Ocean. Mar Biol 5: 275-282. 